\title{
A Fuzzy Controlled LCC HVDC System with AC Voltage and Reactive Power Control
}

\author{
More Anusha ${ }^{1}$, Dola Gobinda Padhan $^{1}$, D. Karuna Kumar $^{1}$ \\ ${ }^{1}$ EEE Departmemt, Gokaraju Rangaraju Institute of Engineering and Technology, Hyderabad, India,
}

\begin{abstract}
The main work focus is on the LCC HVDC reactive power control system with fluid regulated AC voltage. The reactive power and the voltage control capacity of LCC HVDC were examined and demonstrated with controlled condensers. Reactive power control and voltage management have been suggested and associated controllers with variable condensers have been developed on the reverse side of the fuzzy controlled LCC HVDC system. The active corrective side power control is required and a reactive or voltage control has been taken into account in this work. This study looks at the inverter side of the system LCC HVDC with customizable capacitors, reactive power and fluid management of the AC voltage. The usual AC voltage control and PI controller for reactive power is replaced by an injected controller that enhances reaction speed and control. In the MATLAB software with Sim-Power system toolbox, graphs are created using a GUI environment to model the proposed fuzzy-controlled HVDC system.
\end{abstract}

\section{Introduction}

The switch takes place in a switched converter line by AC system voltage. This leads to problems essential to continuous, confident turning at very low ac system voltages, e.g. during breakdowns of the ac system. The ac system is very poor if the [short circuit power ratio at connection] ratio is lower than 2. Certain HVDC systems with dc lines perform fine with ratios of less than 1.5. Some of these difficulties were overcome by the use of condenser series in the HVDC converter in recent years. In addition, the rise in reactive power consumption with the increase of transferred dc power must be taken into account when designing the system and controlling the system design. The HVDC (LCC HVDC) switched-line conversion converter still operates in multiple centuries MW of bulk-power transmission, as a power transmission for numerous applications is efficient, reliable and economical. The reactive power consumption originates after voltage switching from the fire of thyristors which actually delayed waveform current shapes[1]. Thus, both corrector and inverter sides of a system absorb the reactive power. However, the corrective agent for transmitting AC systems must be loaded and response energy is pulled naturally from the network, as with other loads. In contrast, from the point of view of the receiving end $\mathrm{AC}$ system the invertor serves as the power producer and should therefore accept its reactive load share. The fact is, however, that the reactive energy is absorbed instead than generated, thus reducing its degree of reactive energy consumption. Additionally, when reactive power assistance is more needed with passive reactive power adjustment on the inverter side, reactive power generation tends to decrease under rapid DC voltage dippers. The minimal extinction angle controls also raise their spark angle, which results in more reactive energy use and further AC voltage drops. These operational qualities are clearly un-favourable and the circumstance may require FACTS devices like STATCOM, SVC and so on. In contrast, the inverter itself, especially in the course of large AC disruptions, has extremely small or zero receptor voltage levels at a steady status and $\mathrm{AC}$ voltage control. There is very low inverter performance. The reactive power or voltage control of the inverters should not be done at the price of a small degree of active energy transmission, as stable active power transfer is essential for the main task of the HVDC connection. The advantage of the reactive power control inverter can therefore be optimized.

\section{LCC HVDC SYSTEM}

Figure 1. shows an LCC HVDC system and an invertercontrolled AC system[19-21]. Figure 1. LCC HVDC was founded in the Soviets in 1950 (Kashira-Moscow) and in Sweden in 1954. (Gotland). In both systems, mercury valves were used. Initially, thyristor valves have been 
deployed to the Eel River system in Canada in 1972. The adoption of thyristors resulted in a rapid growth in the installed capacity of HVDC systems due to the superior dependence on thyristor technology. In recent years, significant reliability improvements and compact designs of high-power thyristor systems have spurred the enormous expansion of HVDC applications (up to $8.5 \mathrm{kV}$, $4 \mathrm{kA}$ ). The LCC HVDC has been powered by the following power transmission types:

- Transmission of cables in submarines and underground Long distance bulk power transmission using overhead lines - Asynchronous connections among ac system. LICC HVDC is a useful alternative for extending or increasing the power system connections with its technological capacity, paired with economic advantages and low operational losses. An overview of HVDC systems of LCC is provided in this Appendix, covering general loop configuration and operating features. At the conclusion of the appendix is a list of LCC HVDC programe in operation.

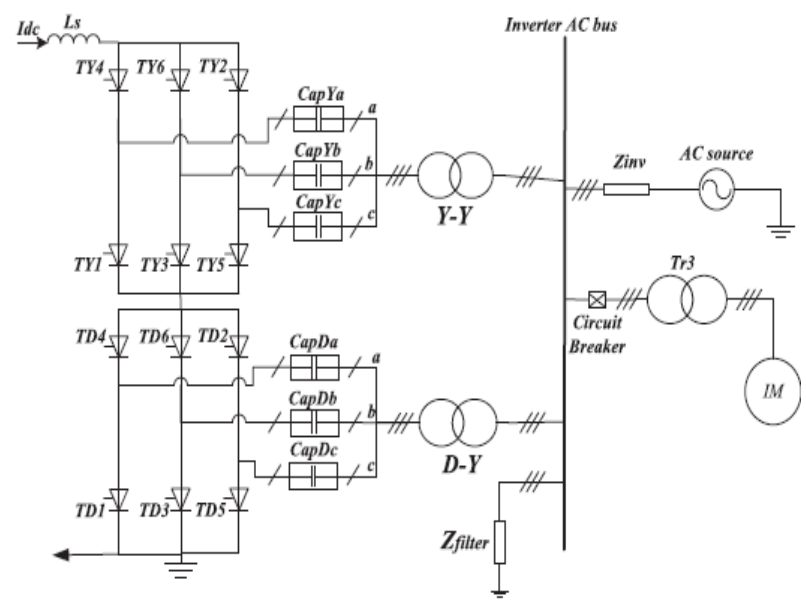

Fig-1: LCC HVDC Configuration.

\section{SYSTEM CONFIGURATION}

In many respects, In order to suit operational needs, HVDC transmission systems can be adjusted. The simplest configuration is the rear-to-back link where 2 converters are situated at the same place without a transmission line. Monopolar HVDC is a low-voltage earth (or sea) or metal conductor, which employs a single high-pressure conductor line. Recent schemes have reduced the usage of Earth Return because to environmental resistance. The most common setup is the bipolar link. Figure 2 illustrates a simplified one line diagram that illustrates a two-terminal bipolar HVDC transmission system. The ground on one terminal with a metallic background is produced Some existing systems connect multi-terminal lines to three or more terminals at different places. There are several systems. Some LCC HVDC systems additionally allow the parallel converters to be operated at the end of a transmission line.

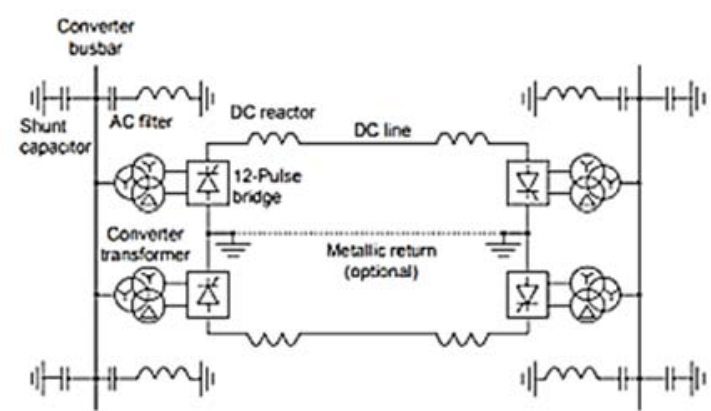

Fig-2: A 2-terminal HVDC system single line diagram

\subsection{Converter}

The converter processes the energy from ac to dc. It is usually equipped with a 12 pulsed system to link two 6 pulsed bridges on the dc side. The conversion control controls the valve switching. The converter of acid to dc is the power-fluid converter and the converter is a dc to ac power-fluid. References 4 and 5 detail the conversion principle and the waveforms associated with such conversions.

\subsection{Converter Transformers}

In accordance with the rated dc voltage, the transformer regulates the voltage supplied to the van bridges. The transformer is equipped with a stellar-star-delta three-way transformer or a combination of star-star and star-delta transformers. The transformer can be delivered in individual components or in tri-phases. Usually, a leakage reaction of approximately $10-18$ percent reduces the current during a short circuit problem in the bridge arm.

\subsection{Harmonic Filters}

The transforming action on ac and dc sides provides harmonic current and tension. An ac-side pulse-number converter produces harmonics with the order $\mathrm{np} \pm 1$ $(\mathrm{n}=1,2,3 \ldots)$. Installed AC filters to absorb the harmonics and minimise the voltage distortion below the necessary level. Tuned filters and high-pass filters are used as ac filters. The sequence of harmonics is $n p$ on the dc side. DC filters are used to remove harmonics in the dc line using dc reactors. DC filters are not required for cable or back-to-back systems.

\subsection{Shunt Capacitors}

In a continuous operation, a switched line converter uses around $60 \%$ reactive power from the active or dc transmitted power. The shunt condensers supply the reactive power needed to sustain the AC BUS voltage converter with the ac bus converter. As the power of an ADC changes to supply sufficient power for an LCC HVDC converter, these condensers are often segmented 
and converted to circuit interrupters. In general, some or all shunt condensers are designed as Acharmonic filters.

\subsection{Reactors}

The DC reactor provides a harmonic dc voltage decrease in the dc line to help the dc current smooth down. The dc reactor also helps restrict the crest current when the dc line is short-circuited. It is noteworthy that the transformer inductance also greatly contributes to these functions.

\section{PROPOSED REACTIVE AC VOLTAGE CONTROLLER}

The reactive power controller proposed on the inverter with the extinguishment angle, measurement and error signals Qref, Qmeas and Qerror being respectively reactive power-reference signals, metric signal and error signals $\mu$ order, $\beta$ meas, and $\mu$ error. A fluid controller can show that the extinguishing angle reference is produced by minimising the reagent power error. In figure 3 , where the AC voltage and measured data are inverted by Vref and Vmeas, the suggested inverter controller is depicted. A FUZZY controller is employed to provide a shot angle by minimizing the $\mathrm{AC}$ voltage error, as shown in Fig. 3

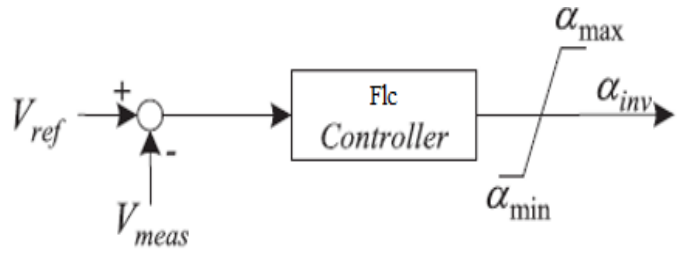

Fig-3: AC Voltage Controller Proposed Inverter

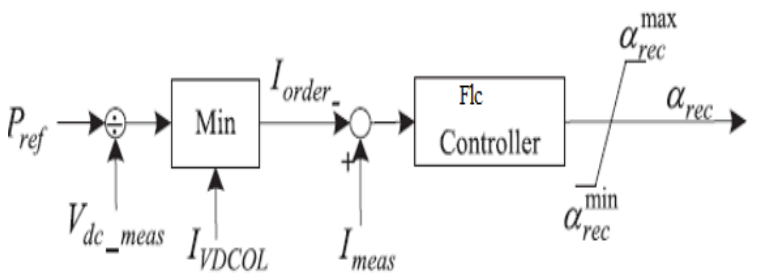

Fig-4: Active Power Controller Correction

\section{FUZZY LOGIC CONTROLLER}

Innovative technology is Fuzzy logic for the enhancement of conventional design of systems with technical talents. By flippant logic, we can circumvent the need for rigorous mathematical representation A human operator is much more successful in conducting a procedure than an actual analysis technique controller. The control approach based on intuition and expertise should therefore be simulated and viewed as heuristic choice or rule of thumb. Fuzzy, a technical word based on human intuition, addresses ambiguity or vaguency on the academic and technology arena.
FLC has, in the last few years, been one of the most active study fields for the application of fuzzy set theory. A fuzzy set is an extension of a common set in which only one of two values 0 and 1 can be the membership function (MF). The following can be defined as a fuzzy set.

Fuzzy puts A into a world of talk $U$ is described by an MF [1]: $U$ [2] and, in the interval [2], associates each $x$ of $U$ with a number $0 \mathrm{~A}(3)$ which represent $\mathrm{x}$ in $\mathrm{A}$.

\subsection{Fuzzy Controller Model}

Fuzzy modelling is the method used to describe system features using fuzzy inference principles. The approach is characterized by the ability to express a nonlinear system which is linguistically complicated. However, it is incredibly handy to find rules and adjust the reasoning's membership functions. Usually fuzzy controllers with floating rules are designed These fugitive rules are either obtained by domain specialists or by monitoring persons who govern them at the moment. The membership of fuzzy sets is based on information provided by the experts in the field and/or observed control actions. These regulations and membership features must be modified. This means that controller performance must be assessed and performance-based adjustment of membership rules and regulations. It will take time for this process. The basic Fuzzy control configuration based on Figure 5 has 4 key components, i.e. I fluctuation, (ii) knowledge basis, (iii) inference engine and (iv) fluctuation.

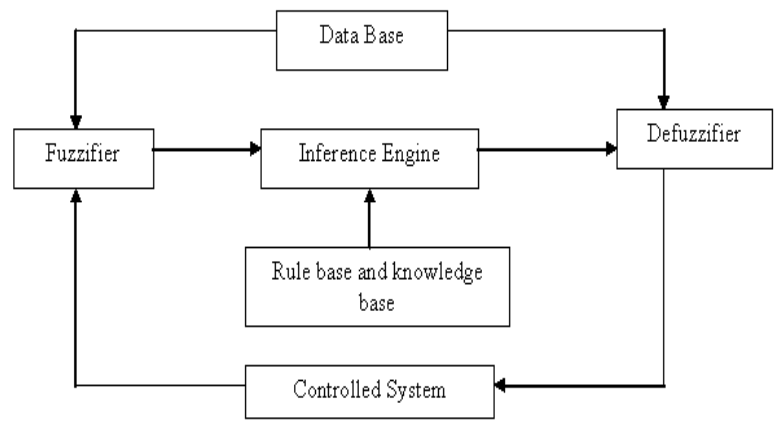

Fig-5: Fuzzy Controller Structure

\subsubsection{Fuzzification}

In specific, input universes of speech, fuzzing maps from crooked input to fuzzy set. So it is mapped to the level of membership to A for a certain input value $\mathrm{x}$. (x). The following functions are part of the fuzzification. The input variable value is measured

1. Conversion of the range of input values to the relevant discourse universe.

2. Carries out a function of fuzzification which converts input data into suitable language variables that can be considered to be fuzzy sets. 


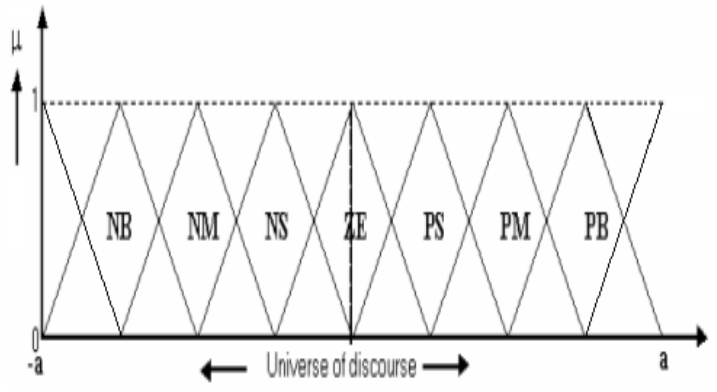

Fig-6: Functions for Three-way membership

\subsubsection{Knowledge Base (KB):}

The basis of knowledge includes the input and output variable definitions of fuzzy MF and the appropriate control rules that specify the control action using language terms.

The database and language control rule basis are provided.

1. This database contains the essential definitions to identify language control rules and to manipulate FLC fuzzy data.

2. The principle basis of the supervision and control policy of the domain experts is characterized by a set of language control rules.

\subsubsection{Mechanism of inference:}

The decision - to make sense. This plays an important part in containing a range of fluid regulations such,

If $x, a, y, b, z, c$ is the case

Where $\mathrm{x}, \mathrm{y}$ and $\mathrm{z}$ are inputs and outputs, the language variables are two: $\mathrm{A}, \mathrm{B}$ and $\mathrm{C}$ are the linguistic ones.

It is the nucleus of an FLC and is capable of simulating human decision-making, with varying participation and deduction rules, based on fluorescence controls.

In general, fuzzy input systems map fuzzy input sets are the relationship of input to output fuzzy sets with fuzzy rules.

\subsubsection{Defuzzification:}

Converts defuzzification to the numerical determination of language variables. In this work, the centroid defluence method is employed.

(1) A mapping scale which translates the input variable value range into the associated discourse universe.

(2)Defuzzification, which produces an inferred fuzzy control action that is not fuzzy.

\section{SIMULATION RESULTS}

This section presents the simulation results of a fuzzy controlled LCC HVDC system with AC voltage and Reactive Power Control. The nominal operating point for both cases is designed so that the inverter side is absorbing zero reactive power and sending rated active power at rated $\mathrm{DC}$ and $\mathrm{AC}$ voltages. The capacitor banks are removed and transformer turns ratio is modified to meet the rated working condition. The values of Capacitors are $547 \mu \mathrm{F}$ and its voltage level is chosen to be $110 \mathrm{kV}$.

\subsection{Reactive Power Control}

In this Simulation, the reactive power reference is initially set to zero and changes to -150 MVar at $3.1 \mathrm{sec}$, then increases to $150 \mathrm{MV}$ ar at $4.6 \mathrm{sec}$ and finally changes back to zero at $6.1 \mathrm{sec}$. Negative reactive power indicates that the inverter is exporting reactive power to the $\mathrm{AC}$ system.

It can be seen that form Fig. 8 and Fig. 13 that measured reactive power successfully tracks the reference and is able to achieve zero steady-state reactive power consumption. It can also be observed that inverter can export reactive power if needed.

At the same time, active power transfer on the DC link is controlled at the rated value which is shown in Fig. 8 and Fig. 13. The response of the DC active power at the instants of step changes of the reactive can be explained by considering controller actions.

For example when the reactive power reference is increased, the inverter firing angle is decreased according to the controller. This decrease of inverter firing angle leads to a decrease of the DC voltage. Therefore the DC power drops transiently as the DC current cannot be changed instantly. Similarly when the reactive power reference is decreased, there is a transient increase of the DC active power. Since the change of the reactive power is achieved by modifying the firing angles, the DC voltage also changes.

Fig. 9 and Fig. 14 shows that the DC current is slightly changed to keep a constant active power level.

From Fig. 11 and Fig. 16 it can be seen that the capacitor voltages are well balanced by the capacitor voltage controller.

Fig. 7 and Fig 12 shows how the capacitor currents charge and discharge the capacitors.

\subsection{System responses with reactive power reference Step changes}

\subsubsection{Without Fuzzy Controller:}

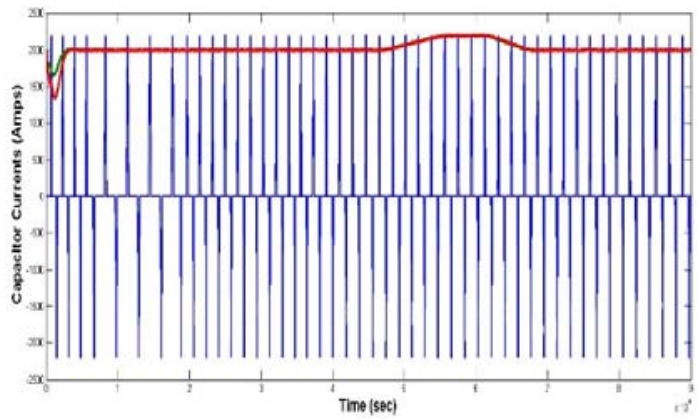

Fig-7: Capacitor currents with respective to time 


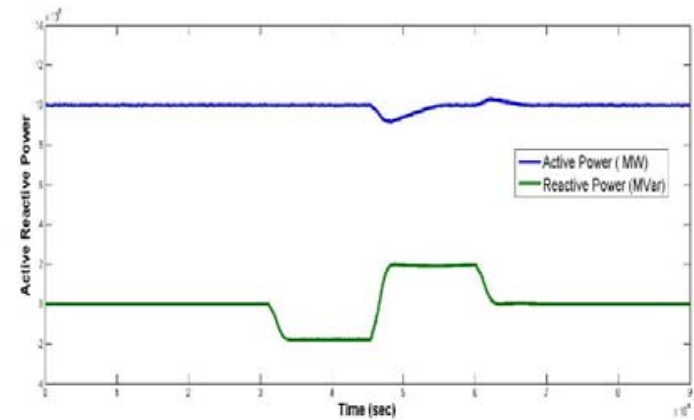

Fig-8: Reactive Power Consumption at Inverter and Active Power Transfer

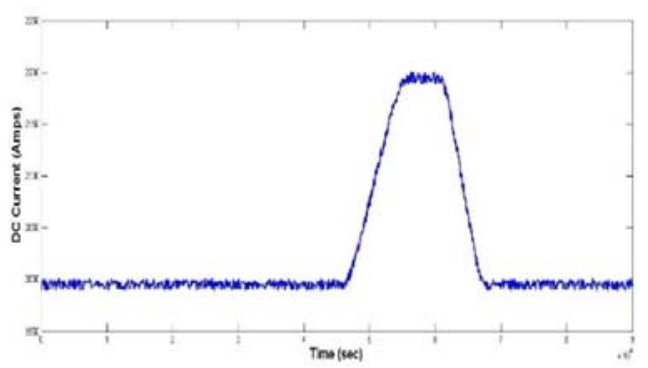

Fig-9: DC current with respective to time

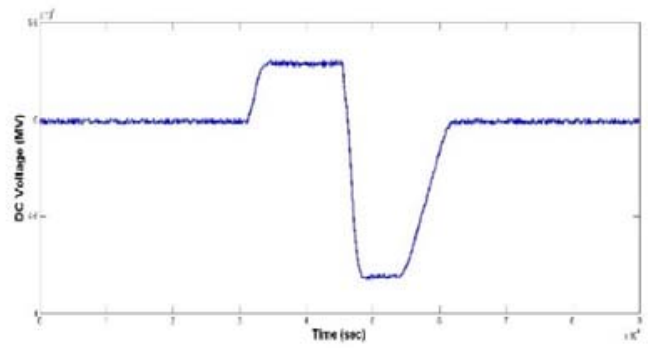

Fig-10: DC Voltage

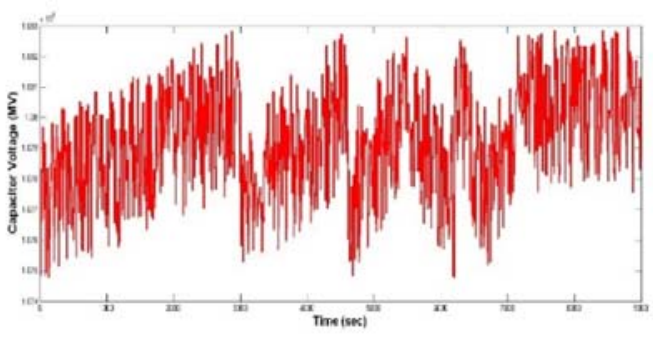

Fig-11: Capacitor Voltage

\subsubsection{With Fuzzy Controller:}

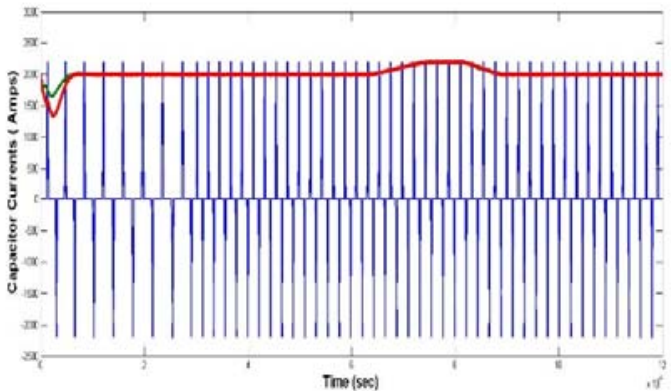

Fig-12: Capacitor Currents with Fuzzy Controller

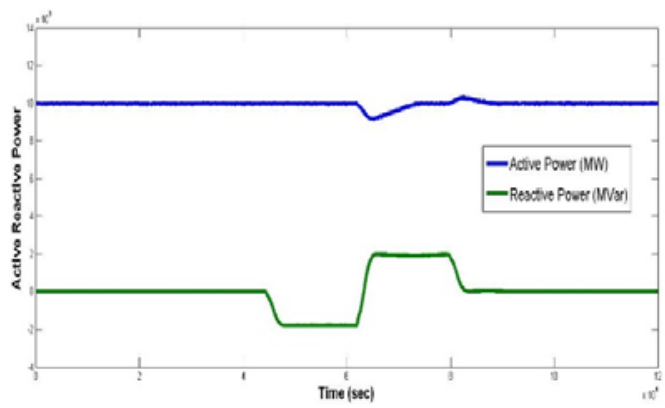

Fig-13: Reactive Power Consumption at Inverter and Active Power Transfer with Fuzzy Controller

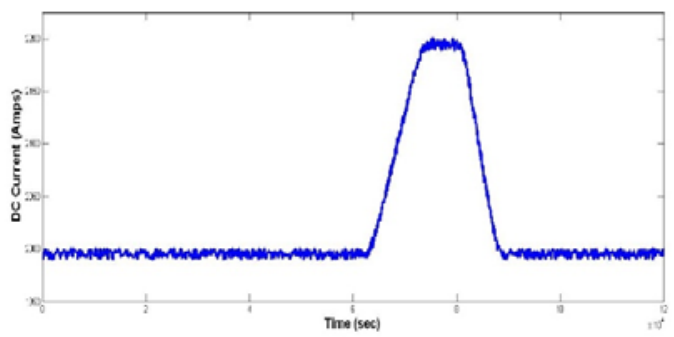

Fig-14: DC current with Fuzzy Controller

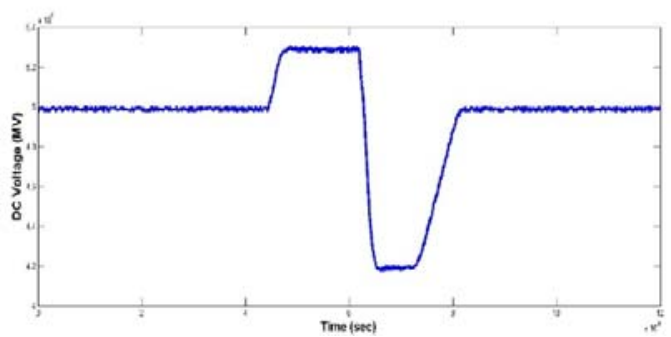

Fig-15: DC Voltage with Fuzzy Controller

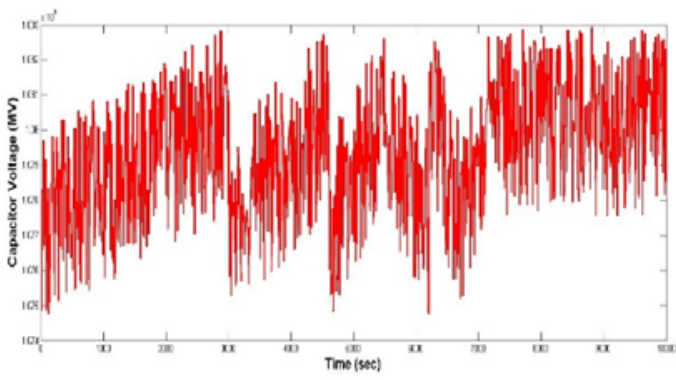

Fig-16: Capacitor Voltage with Fuzzy Controller 


\section{CONCLUSION}

This study examined and showed how reacting power and voltage control is capable of the LCC HVDC system, with its changeable condensers. Reactive power control, voltage control and accompanying controllers were designed on the inverter side of the LCC HVDC system with controlled condensers. The reactive power controllers or voltage controllers should also be used to control the power on the rectifier side and this is part of the task. Real time digital simulation data demonstrate the effective reactive capability of the suggested system (RTDS).The proposed Fuzzy Logic idea, which supports accurate condenser management and efficiency of the system by decreasing reactive power consumption.

\section{References}

1. P.Kundur,: McGraw- Hill, (1994)

2. RP Burgess, JD Ainsworth, HL Thanawala, M Jain, and R. Burton, CIGRE 14-104, (1990)

3. B. Andersen, D. Monkhouse, and R. Whitehouse, CIGRE, (1998)

4. Y. Zhuang, R. W. Menzies, O. B. Nayak, and H. M.Turanli, IEEE Transactions on Power Delivery, vol. 11, 958- 964, (1996)

5. O. B. Nayak, A. M. Gole, D. G. Chapman, and J. B. Davies, 9, (1994)

6. M. De Oliveira, M. Poloujadoff, A. Le Du, and P. G. Therond, International Journal of Electrical Power \& Energy Systems, 16, (1994)

7. J. W. Feltes, B. D. Gemmell, and D. Retzmann, IEEE Power and Energy Society General Meeting, (2011)

8. S. V. Bozhko, R. Blasco-Gimenez, L. Risheng, J. C. Clare, and G. M. Asher, IEEE Transactions on Energy Conversion, 22, (2007)

9. L. Yong, L. Longfu, C. Rehtanz, S. Ruberg, and L. Fusheng, IEEE Transactions on Power Electronics, vol. 27, pp. 3908-3923, (2012)

10. D. Hanguang, W. Yuhong, L. Xingyuan, D. Hongqiang, and M. Zhiqiang, Power and Energy Engineering.

11. R. Blasco-Gimenez, N. Aparicio, S. Ano-Villalba, and S. Bernal-Perez, IEEE Trans. Ind. Electron., 60, 6, (2013)

12. D. Renchang, M. D. Hwang, Q. Wei, W. Weiguo, L. Xiaopeng, and X. Yan, Proc. IEEE Power \& Energy Soc. General Meeting, (2015)

13. Y. Xiaoran, Y. Fenyan, F. Xiazhou, and X. Zheng, Proc. Int. Conf. Power Syst. Technol., (2014)

14. S. Oh, G. Jang, S. Moon, Y. Jeon, and J. Choo, Proc.IEEE/PES Transm. Distrib. Conf. Exhib., 3, (2002)

15. G. Balzer and H. Muller, Proc. 7th Int. Conf. ACDC PowerTransm., (2001)

16. A. M. Gole and M. Meisingset, Power Eng. J., vol.
16, pp. 129-134, (2002)

17. J. Reeve, J. A. Baron, and G. A. Hanley, IEEETrans. Power App. Syst., 87, 10, (1968)

18. M. Meisingset and A. M. Gole, Proc. IEEE Power Eng. Soc.Winter Meeting, 2, (2001)

19. Sridevi, J., Rani, V.U., Rao, B.L., 2019 IEEE International Conference on Electrical, Control and Instrumentation Engineering, ICECIE 2019 Proceedings (2019)

20. S. Seshadri, M. Kavitha and P. B. Bobba, 2018 International Conference on Power, Instrumentation, Control and Computing (PICC), 2018, pp. 1-6

21. B. T. P. Singh, B. P. Babu and Y. Satyavani, 2019 IEEE Transportation Electrification Conference (ITEC-India), 2019, pp. 1-6 